\title{
Korrespondenzen.
}

\section{Brasilianischer Buba.}

Von Dr. A. Splendore, Direktor des Bakteriologischen Laboratoriums des Portugiesischen Hospitals in S. Paulo.

In der Deutschen medizinischen Wochenschrift No. 11 (16. März 1911) erschien ein Referat meiner unter gleichem Titel im Archiv für Tropenhygiene pułlizierten Arbeit, das nicht ganz richtig den Inhalt wiedergab.

Der Name „Buba Brasiliana", mit dem Breda eine Krankheit von Individuen, die aus Brasilien kamen, bezeichnete, ist nicht richtig gewählt, weil hier in Brasilien dieser Name „Buba“" von den Aerzten bloß der Framboesia tropica (Pian) beigelegt wird; das Volk hingegen nennt jedes Geschwür Buba. Die von Bred a beschriebene Krankheit ist von der Framboesie verschieden.

In Brasilien gibt es drei Krankheitsformen mit framboesieartigem Charakter. 1. Die echte „Buba“" $(\mathrm{Pi}$ an), die durch Spirochaeta pertenuis (Castellani) erzeugt ist, 2. eine mykotische Erkrankung, die als eine spezielle Form der Blastomykose anzusehen ist, und 3. eine Protozoencrkrankung in einer neuen Form der Leishmaniose.

Diese letzteren zwei Formen sind hauptsächlich in den mit Mucosa ausgekleideten Höhlen lokalisiert und jeder bisher bekannten Behandlung unzugänglich.

Die Charaktere dieser Krankheiten stimmen mit den von Breda beschriebenen vollkommen überein. In einem Spezialartikel werde ich auf die näheren Details zurüekkommen. 